\section{A Check for updates}

Cite this: Green Chem., 2021, 23, 412

\title{
Thio-assisted reductive electrolytic cleavage of lignin $\beta-0-4$ models and authentic lignin $\uparrow$
}

\author{
Zhen Fang, (D) a,b Michael G. Flynn, ${ }^{a}$ James E. Jackson (D)*c and Eric L. Hegg (D) *a,b
}

Received 23rd October 2020, Accepted 3rd December 2020 DOI: $10.1039 / \mathrm{dOgc03597a}$ rsc.li/greenchem

\begin{abstract}
Avoiding the use of expensive catalysts and harsh conditions such as elevated temperatures and high pressures is a critical goal in lignin depolymerization and valorization. In this study, we present a thioassisted electrocatalytic reductive approach using inexpensive reticulated vitreous carbon (RVC) as the working cathode to cleave the $\beta$-O-4-type linkages in keto aryl ethers. In the presence of a pre-electrolyzed disulfide $\left(2,2^{\prime}\right.$-dithiodiethanol) and a radical inhibitor (BHT) at room temperature at a current density of $2.5 \mathrm{~mA} \mathrm{~cm}{ }^{-2}$, cathodic reduction of nonphenolic $\beta-O-4$ dimers afforded over $90 \%$ of the corresponding monomeric $\mathrm{C}-\mathrm{O}$ cleavage products in only $1.5 \mathrm{~h}$. Extended to DDQ-oxidized poplar lignin, this combination of electric current and disulfide, applied over $6 \mathrm{~h}$, released $36 \mathrm{wt} \%$ of ethyl acetate soluble fragments and $26 \mathrm{wt} \%$ of aqueous soluble fragments, leaving only $38 \mathrm{wt} \%$ of insoluble residue. These findings represent a significant improvement over the current alone values ( $24 \mathrm{wt} \%$ ethyl acetate soluble; 22 wt\% aqueous soluble; 54 wt\% insoluble residue) and represent an important next step in our efforts to develop a mild electrochemical method for reductive lignin deconstruction.
\end{abstract}

\section{Introduction}

Lignin is the most abundant renewable aromatic biopolymer on earth, and it has been recognized as a promising feedstock for fuels and chemicals. ${ }^{1-5}$ The complex three-dimensional structure and diverse functionalities of lignin, however, complicate the deconstruction of this macromolecule. The alkyl and aryl units of lignin's heterogeneous polymer skeleton are connected via ether or carbon-carbon bonds, ${ }^{1}$ with the $\beta-\mathrm{O}-4$ ether linkage being the most abundant, accounting for approximately $50 \%$ and $60 \%$ of the linkages in softwoods and hardwoods, respectively. ${ }^{1}$ Efficient cleavage of the $\beta-\mathrm{O}-4$ linkage is therefore critical for lignin depolymerization, and indeed, aerobic oxidation, ${ }^{6-11}$ reduction, ${ }^{12-14}$ and hydrolysis ${ }^{15-17}$ of this bond have been extensively studied as depolymerization strategies. ${ }^{1,2,4,5}$

An ideal lignin depolymerization process would (i) avoid costly catalysts, ${ }^{18,19}$ severe conditions such as high pressures/ temperatures, ${ }^{12,14,20}$ and the use of hazardous gaseous reagents such as hydrogen; (ii) produce a minimum amount of

\footnotetext{
${ }^{a}$ Department of Biochemistry \& Molecular Biology, Michigan State University, 603 Wilson Rd, East Lansing, Michigan 48824, USA. E-mail: erichegg@msu.edu

${ }^{b}$ Great Lakes Bioenergy Research Center, Michigan State University, 1129 Farm Lane, East Lansing, Michigan 48824, USA

${ }^{c}$ Department of Chemistry, Michigan State University, 578 S Shaw Ln, East Lansing, Michigan 48824, USA. E-mail: jackson@chemistry.msu.edu

$\dagger$ Electronic supplementary information (ESI) available. See DOI: 10.1039/ dogc03597a
}

chemical waste; and (iii) retain the maximum amount of the feedstock carbon and energy content. ${ }^{21}$ Compared to conventional reductants and oxidants, electric current is an inherently clean and inexpensive reagent, capable of cleaving lignin model compounds $\mathrm{s}^{22-24}$ and depolymerizing real lignin. ${ }^{25}$ Because only electrons and protons are removed or added during electrolysis, generation of additional pollutants or reagent wastes is largely avoided. ${ }^{26}$ Moreover, the counter-electrode cell offers the opportunity to perform additional desired organic transformations, or simply to split water. For instance, in a reductive process, the resulting pure $\mathrm{O}_{2}$ byproduct from water-splitting is a "free" non-polluting oxidant which may be discharged or used in other non-electrolytic reactions. ${ }^{27,28}$ Most existing reports on electrolytic lignin decomposition describe anodic oxidation, beginning with the pioneering studies by Utley et al. where mechanisms of electro-oxidative cleavage of lignin models were explored using nickel anodes in various solvent systems. ${ }^{29}$ Most related oxidative strategies ${ }^{30,31}$ have generally required expensive electrode materials such as $\mathrm{Au}^{32}$ or $\mathrm{IrO}_{2},{ }^{33}$ or the assistance of photo-catalysts. ${ }^{34,35}$ Some reductive approaches have also used electrodes made of catalytic metals such as RANEY® nickel or ${ }^{\circledR}{ }^{22,23,36}$ Electrocatalytic hydrogenation/hydrogenolysis (ECH) with such metal electrodes typically leads to saturation of potentially desirable aromatic products, though we have recently identified promising strategies to modulate selectivities. ${ }^{37}$ These further reactions add to the complexity of the cleavage product streams, complicating isolation, purification, and further direct utilization of targeted products. Thus, the development 
of a simple, low-cost approach to selectively and efficiently cleave the ether bonds in $\beta-\mathrm{O}-4$ linkages remains a critical need for effective lignin depolymerization and upgrading to useful products.

We previously reported the successful reductive cleavage of lignin-relevant $\alpha$-keto aryl ether dimers by various small organic thiols. $^{38,39}$ This bio-inspired approach formed phenol and acetophenone quantitatively from 2-phenoxyacetophenone after $24 \mathrm{~h}$ treatment with 100 eq. $\beta$-mercaptoethanol (BME) in refluxing acetonitrile. The resulting disulfide byproduct could

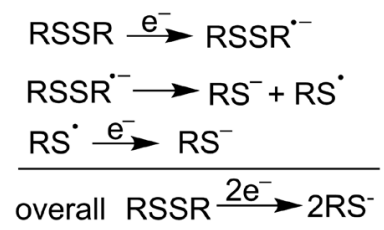

Scheme 1 Schematic illustration of disulfide reduction via successive one-electron transfer steps.

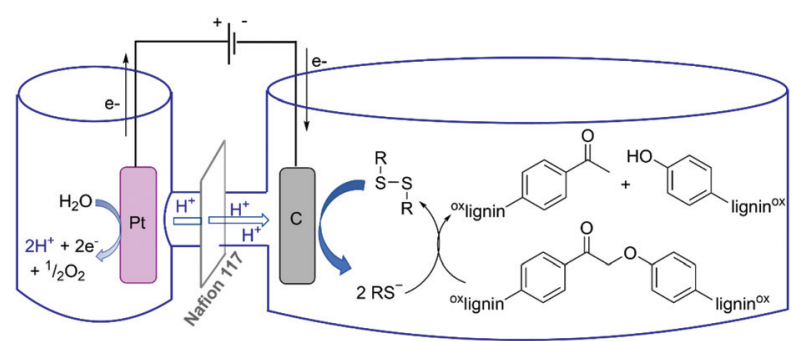

Fig. 1 Potential schematic mechanism of lignin deconstruction in a thio-assisted electrolytic system. theoretically be reduced back to the active thiol by various reductants. Of greatest interest here would be electrochemical reduction, regenerating the thiolate with no reagent byproducts (Scheme 1). ${ }^{40}$ This approach could potentially lead to a sustainable cycle connecting electrochemical reduction to lignin cleavage via thiols as small diffusible redox carriers (Fig. 1). We now report a thio-assisted electro-reductive approach using inexpensive reticulated vitreous carbon (RVC) as the working cathode to cleave $\alpha$-oxidized $\beta$-O-4-type linkages in model compounds and in lignin samples. This study, intended to extend our biomimetic thiol-mediated reductive cleavage method to electrochemical reduction, reveals additional cleavage processes that are not completely interpretable within the above mechanistic framework, but promise significant value nonetheless.

\section{Results and discussion}

\section{Thio-assisted electrolysis of 2-phenoxyacetophenone}

Treatment of 2-phenoxyacetophenone ( $4.7 \mathrm{mM}$ in $20 \mathrm{~mL}$ ) with current alone was first performed as a control at room temperature in an H-type electrochemical cell. DMF, the polar aprotic solvent that most effectively promoted keto aryl ether bond cleavage in the previous $\mathrm{S}_{\mathrm{N}} 2$ mechanism, ${ }^{38}$ was utilized as the solvent on the cathode side. For most experiments, a constant current of $5 \mathrm{~mA}$ was applied, passing through a $2 \mathrm{~cm}^{2}$ reticulated vitreous carbon (RVC) cathode (Table 1), providing an area-based current density of $2.5 \mathrm{~mA} \mathrm{~cm}{ }^{-2}$; herein these conditions are simply described as " $5 \mathrm{~mA}$ ". Interestingly, current alone cleaved 2-phenoxyacetophenone (compound I in Table 1) to phenol and acetophenone in $2.5 \mathrm{~h}$ (entry 1), although the substrate barely decayed in the first $45 \mathrm{~min}$

Table 1 Cathodic electrolysis of 2-phenoxyacetophenone (I, $4.7 \mathrm{mM}$ ) in the presence of 2,2'-dithiodiethanol (hereafter referred to as RSSR, $4.7 \mathrm{mM}$ ) with $5 \mathrm{~mA}$ electric current $\left(2.5 \mathrm{~mA} \mathrm{~cm}{ }^{-2}\right)$; anode : $\mathrm{Pt}$ wire in $\mathrm{pH} 8$ phosphate buffer

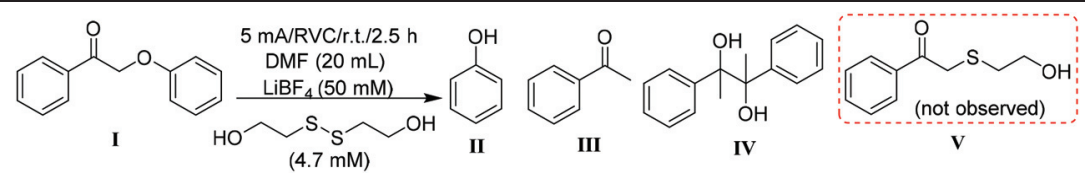

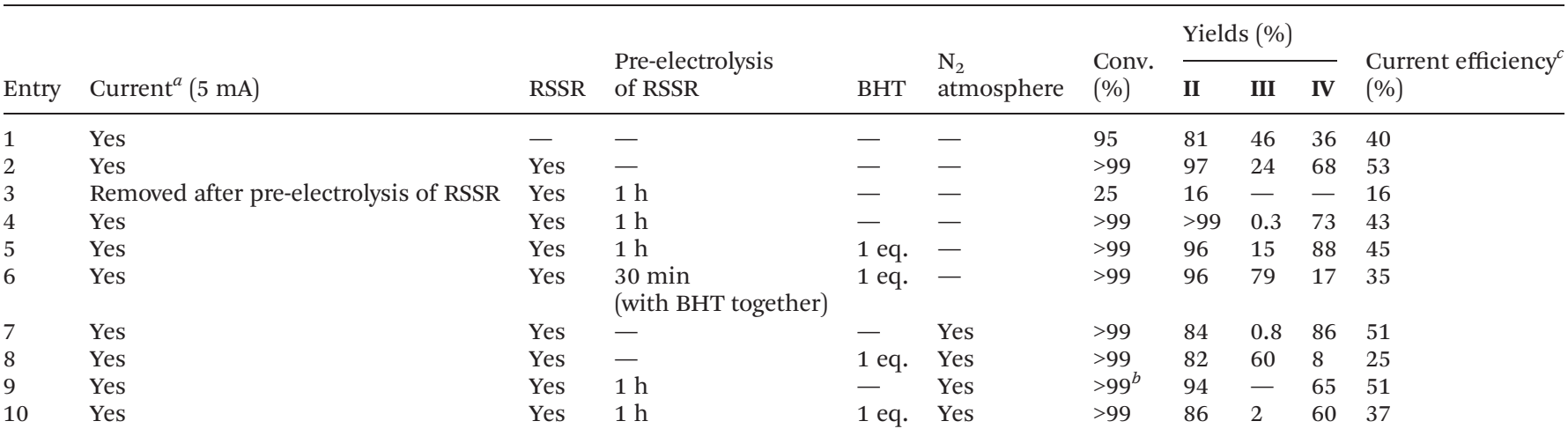

${ }^{a}$ Passage of two equivalents of electrons required approximately $1 \mathrm{~h}$ under these conditions. ${ }^{b}$ 1-Phenylethanol (6\%) was formed as well. ${ }^{c}$ Preelectrolysis time was included in the calculation. 

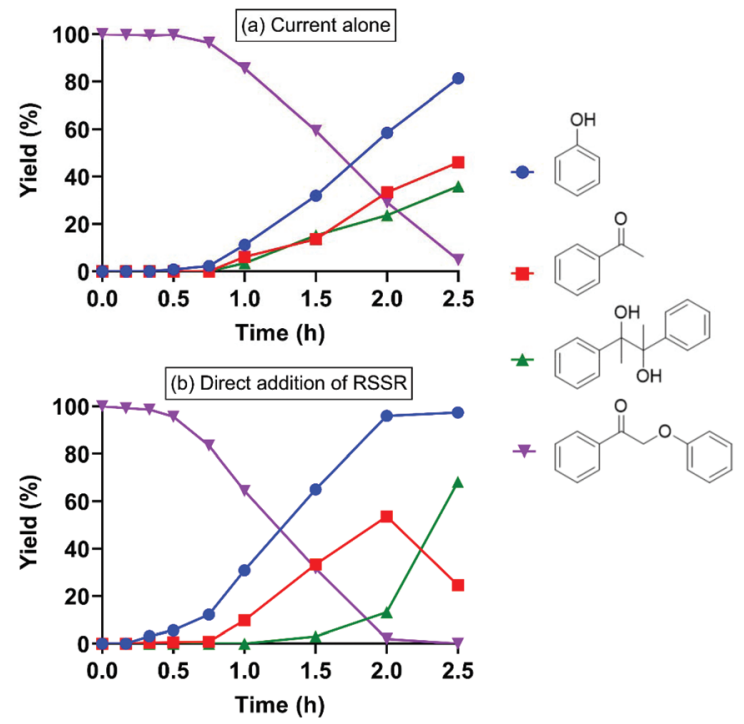

Fig. 2 Electrolysis of 2-phenoxyacetophenone (compound I) under $5 \mathrm{~mA}$ at room temperature with (a) current alone; and (b) current with direct (i.e., applied simultaneously with) addition of RSSR.

(Fig. 2a). Pinacol (compound IV in Table 1), known to form from the reductive dimerization of acetophenone, ${ }^{41}$ was also produced as the reaction progressed. As expected, successful cleavage required the $\alpha$-keto (oxidized) form of this $\beta$-O- 4 linkage model; no reaction occurred with the parent alcohol analog under $5 \mathrm{~mA}$ electric current alone (Fig. S1 $\dagger$ ).

Stoichiometrically, only two equivalents of thiolate are needed to reductively cleave 2-phenoxyacetophenone via a reaction mechanism consisting of an $\mathrm{S}_{\mathrm{N}} 2$ displacement of phenoxide by thiolate, followed by nucleophilic attack of thiolate on the thioether intermediate (compound $\mathbf{V}$ in Table 1) to replace 1-phenylethen-1-olate (the enolate of acetophenone). ${ }^{38}$ To probe the susceptibility of disulfide to electrolytic cleavage and its effect on the deconstruction of lignin dimer model compounds, 1 equivalent of 2,2'-dithiodiethanol (the disulfide derived from $\beta$-mercaptoethanol oxidation) was included in the DMF solution in the cathode cell (entry 2). The 2-phenoxyacetophenone cleavage displayed a reaction profile similar to that in Fig. 2a, with virtually no formation of phenol and acetophenone in the first $1 \mathrm{~h}$ (Fig. $2 \mathrm{~b}$ ) at room temperature. In addition to 2,2'-dithiodiethanol, other disulfides including cystine (Fig. S2 $\dagger$ ) exhibited comparable rates of substrate consumption. The critical nucleophile that cleaved the ether bond in the previous studies, ${ }^{38,39}$ 2-hydroxyethanethiolate (here referred to as $\mathrm{RS}^{-}$), was initially presumed to be the active species in the electrochemically driven reaction. At the $5 \mathrm{~mA}$ current used in these experiments, two equivalents of electrons were calculated to pass through the cathode in $1 \mathrm{~h}$, and the RSSR should ideally then be reduced to 2 equivalents of $\mathrm{RS}^{-}$. Therefore, RSSR was pre-electrolyzed in DMF at $5 \mathrm{~mA}$ for $1 \mathrm{~h}$ to reduce the disulfide, the current was then removed, and the substrate 2-phenoxyacetophenone was added (entry 3 ). The substrate decayed only very slowly (Fig. 3a) under these con-

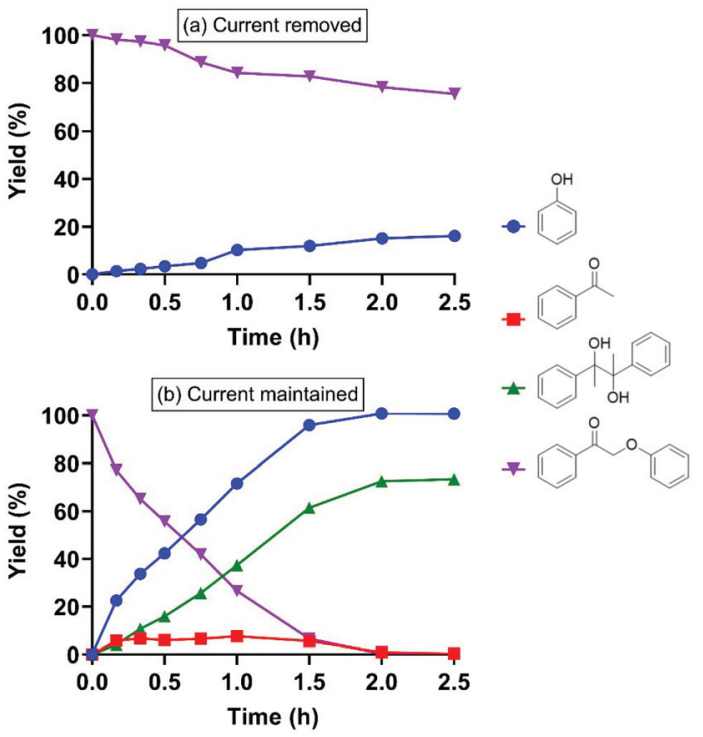

Fig. 3 Effect of flowing current $(5 \mathrm{~mA})$ on cleavage of 2-phenoxyacetophenone (I) with $1 \mathrm{~h}$ pre-electrolyzed RSSR: (a) current was removed after I was added (entry 3); (b) current was maintained throughout the entire reaction (entry 4).

ditions, consistent with our previous finding that heat was required to get reasonable reaction rates in the thiolateenabled dimer cleavage. ${ }^{38}$ In a parallel control, the combination of $\beta$-mercaptoethanol (hereafter referred to as RSH) with either an insoluble $\left(\mathrm{K}_{2} \mathrm{CO}_{3}\right)$ or a soluble $\left(\mathrm{Et}_{3} \mathrm{~N}\right)$ base in DMF also showed little or no cleavage of 2-phenoxyacetophenone at room temperature (Fig. S3 and S4 $\dagger$ ).

When the current was maintained following pre-electrolysis of RSSR, 2-phenoxyacetophenone decayed significantly faster (Fig. 3b). As expected, cleavage was faster after an hour of preelectrolysis (i.e., two equivalents of electrons, the quantity expected to fully reduce the disulfide), than with only $30 \mathrm{~min}$ of pre-electrolysis (Fig. S5 $\dagger$ ). Notably, the thioether (compound $\mathbf{V}$ in Table 1), the critical diagnostic intermediate in the $\mathrm{S}_{\mathrm{N}} 2$ mechanism previously studied, was not observed in the cathode cell. One potential explanation is that some species other than simple $\mathrm{RS}^{-}$was involved in attacking the substrate during electrolysis.

Thiyl radical (referred to as $\mathrm{RS}^{\circ}$ ) formed during the cathodic disulfide reduction might contribute to the substrate decomposition. To probe this possibility, the current was turned off once the RSSR was pre-electrolyzed for $1 \mathrm{~h}$, and then the radical trap butylated hydroxytoluene (BHT) was added together with the substrate (current was still absent). Although 2-phenoxyacetophenone was cleaved to a small extent, the reaction ceased after 45 min (Fig. S6 $\dagger$ ), showing a similar profile to that in Fig. 3a, where BHT was not employed. In addition, when RSSR was pre-electrolyzed for only $30 \mathrm{~min}$, the current removed, BHT added, and the resulting solution stirred for an additional $30 \mathrm{~min}$, no cleavage of substrate was observed (Fig. S7 $\dagger$ ); however, if no BHT was added, a slow reaction did occur (Fig. S8†). In a parallel control, a thiyl radical 
generated from RSH and AIBN (azobisisobutyronitrile) yielded essentially no substrate cleavage in the absence of current (Fig. S9†). Thus, as in the previous thio-based cleavage studies, we infer that dimer cleavage does not involve free thiyl radical processes, ${ }^{38}$ suggesting instead that the electric current forms diffusible electron-carrier species, which activate ether bond cleavage.

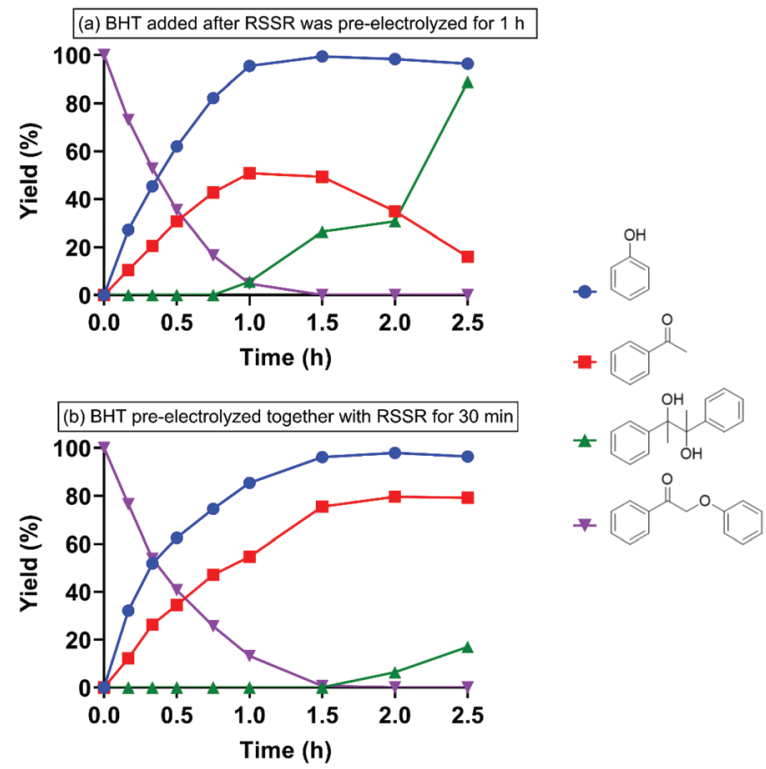

Fig. 4 Effect of BHT on the electrolysis of 2-phenoxyacetophenone (I) using $5 \mathrm{~mA}$ of current. Condition: Prior to the addition of I, (a) BHT was added after RSSR was pre-electrolyzed for $1 \mathrm{~h}$ (entry 5); (b) BHT and RSSR were pre-electrolyzed together for 30 min (entry 6).
In the absence of the radical trap BHT, when RSSR was preelectrolyzed for $1 \mathrm{~h}$ before addition of 2-phenoxyacetophenone substrate, pinacol began forming almost immediately and only small quantities of acetophenone were observed as current flow continued and the starting material was cleaved (Fig. 3b). In contrast, addition of BHT to $1 \mathrm{~h}$ pre-electrolyzed RSSR (entry 5) allowed acetophenone to accumulate to $50 \%$ yield before it was further reduced and dimerized to pinacol (Fig. 4a).

With these results in mind, BHT and RSSR (1:1 molar ratio) were pre-electrolyzed together for $1 \mathrm{~h}$ prior to addition of 2-phenoxyacetophenone and $5 \mathrm{~mA}$ of current was maintained throughout the entire reaction. Compared to pre-electrolysis of RSSR alone (for $30 \mathrm{~min}$ ) in the absence of BHT (Fig. S5 $\dagger$ ), in which acetophenone only accumulated to $14 \%$ yield and up to $70 \%$ of pinacol was formed, with the BHT present in the preelectrolysis mixture (entry 6), 2-phenoxyacetophenone was completely cleaved in $1.5 \mathrm{~h}$ with a quantitative yield of phenol and up to $80 \%$ of acetophenone (Fig. 4b). In addition, no pinacol was observed until all substrate had been cleaved (Fig. 4b) at $1.5 \mathrm{~h}$. Doubling the quantity of BHT used did not lead to a statistically significant change in the reaction profile (Fig. S10†).

To study further the potential role of a disulfide-derived radical species during substrate cleavage in the cathode cell, the effect of $\mathrm{O}_{2}$, a known radical trap, ${ }^{42}$ was evaluated. Even when RSSR was not pre-electrolyzed, the substrate decayed much faster under anoxic conditions; under a $\mathrm{N}_{2}$ atmosphere (entry 7), the reaction was nearly complete after $2 \mathrm{~h}$ with pinacol and phenol being the major products (Fig. 5a), while $40 \%$ of the substrate remained unreacted after $2 \mathrm{~h}$ when the
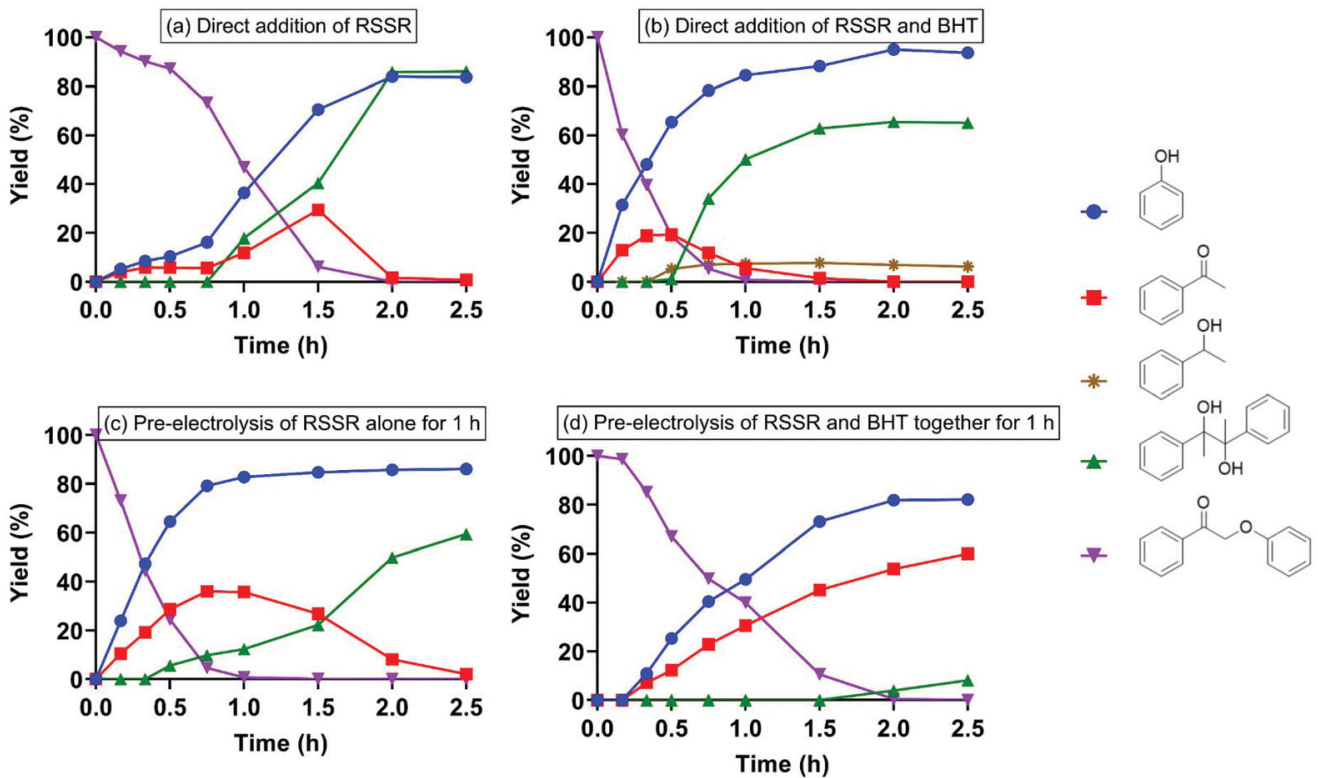

Fig. 5 Thio-assisted cathodic electrolysis of 2-phenoxyacetophenone (I) under $\mathrm{N}_{2}$ atmosphere. (a) Direct addition (i.e., applied simultaneously with) of RSSR (entry 7) with I; (b) direct addition of RSSR and BHT with I (entry 8); (c) RSSR alone was pre-electrolyzed for $1 \mathrm{~h}$ prior to addition of I (entry 9); (d) RSSR and BHT were pre-electrolyzed together for $1 \mathrm{~h}$ prior to addition of I (entry 10). 
(a)

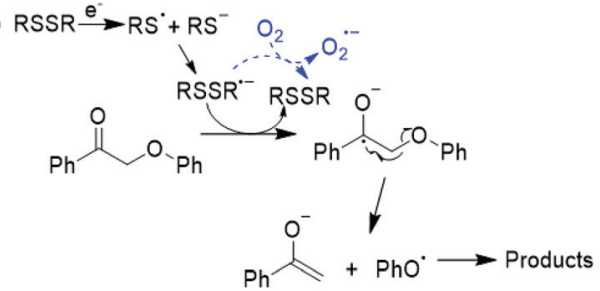

(b) $\mathrm{RS}^{\circ}+\mathrm{O}_{2} \longrightarrow \mathrm{RSO}^{\circ} \longrightarrow \mathrm{R}^{\circ}+\mathrm{SO}_{2}$

Scheme 2 (a) A proposed mechanism to cleave 2-phenoxyacetophenone via a one-electron reduction pathway; (b) potential mechanism of $\mathrm{O}_{2}$ trapping the thiyl radical.

same reaction was performed under fully aerobic conditions (Fig. 2b). Moreover, addition of BHT to reactions performed under $\mathrm{N}_{2}$ (entry 8) again inhibited the formation of pinacol (Fig. 5b), but still showed faster cleavage of 2-phenoxyacetophenone than in the open air (Fig. S11†).

One pathway considered for the $\mathrm{C}-\mathrm{O}$ ether bond cleavage in the keto aryl ether substrate was one-electron reduction by an electron transfer agent. In that scenario, the disulfide radical anion (RSSR ${ }^{-}$) might act as an electron carrier. Oxygen could (a) consume an electron from $\operatorname{RSSR}^{\circ-},{ }^{43}$ slowing the rate of 2-phenoxyacetophenone cleavage relative to that under $\mathrm{N}_{2}$ (Scheme 2a), or (b) react with $\mathrm{RS}^{*}$ or $\mathrm{RS}^{-}$to form the $\mathrm{RSO}_{2}{ }^{\text {* }}$ radical or anion (Scheme $2 \mathrm{~b}$ ). ${ }^{44-46}$ To test this possibility, RSSR was pre-electrolyzed for $1 \mathrm{~h}$ under $\mathrm{N}_{2}$; again, after substrate addition, pinacol and phenol were the major products (entry 9, Fig. 5c). Here, the substrate was completely consumed in only $1 \mathrm{~h}$ while previous controls had required at least $1.5 \mathrm{~h}$. Including BHT during RSSR pre-electrolysis under $\mathrm{N}_{2}$ (entry 10) did not slow the 2-phenoxyacetophenone deconstruction (Fig. 5d), indicating again that the cleavage did not solely depend on the thiyl radical and that oxygen competed to abstract the electron from the electron transfer agent, thereby diverting the reaction.

Importantly, we found that the electrolyte used in this study, $\mathrm{LiBF}_{4}$, was critical in promoting the cleavage of 2-phenoxyacetophenone. $\mathrm{Li}^{+}$, a known ion pairing agent and Lewis acid, ${ }^{47}$ favored the formation of pinacol (Scheme $\mathrm{S} 1 \dagger$ ) and presumably shifted the equilibrium of the cleavage reaction. When $\mathrm{NaBF}_{4}$ was employed as the electrolyte, approximately $50 \%$ of the substrate remained unreacted and pinacol was not observed even after $2.5 \mathrm{~h}$ (Fig. S12 $\dagger$ ). Under these same conditions using $\mathrm{LiBF}_{4}$ as the electrolyte, however, the substrate 2-phenoxyacetophenone was nearly completely cleaved in $1.5 \mathrm{~h}$ and pinacol was formed (Fig. $3 \mathrm{~b}$ ).

Current efficiencies (CE\%) of all reactions were calculated as follows: ${ }^{48}$

$$
\mathrm{CE} \%=\left(\frac{\operatorname{mol}_{\text {prod }} \times F \times n}{C_{\text {total }}}\right) \times 100 \%
$$

where mol $_{\text {prod }}$ is the moles of reduction products (phenol and pinacol); $F$ is the Faraday constant (96485 $\mathrm{C} \mathrm{mol}^{-1}$ ); $n$ is the number of electrons per reaction and $C_{\text {total }}$ is the total charge passed. Overall, entry 2 shows the highest faradaic efficiency $(\sim 53 \%)$.

\section{Thio-assisted electrolysis of other $\beta$-O-4 model compounds}

In our previous study, 2-phenoxyacetophenone was reacted with 100 eq. of $\beta$-mercaptoethanol (BME) and a large excess of insoluble base $\left(\mathrm{K}_{2} \mathrm{CO}_{3}\right)$ in refluxing acetonitrile $\left(\sim 85{ }^{\circ} \mathrm{C}\right)$ for $24 \mathrm{~h}$ to achieve complete cleavage of substrate. ${ }^{38}$ In the present work, however, 2-phenoxyacetophenone was completely decomposed in $1.5 \mathrm{~h}$ at room temperature in the presence of only 1 eq. of 2,2'-dithiodiethanol (the disulfide form of BME) and $5 \mathrm{~mA}$ electric current, producing a quantitative yield of phenol and up to $80 \%$ of acetophenone (Fig. $4 \mathrm{~b}$ ). In addition, the formation of pinacol was inhibited by BHT until after $1.5 \mathrm{~h}$.

Encouraged by the success in thio-assisted electrolytic cleavage of 2-phenoxyacetophenone, we explored this system with other $\alpha$-keto $\beta$-O-4 dimers $(\mathbf{1 a}-\mathbf{c})$ more closely related to real lignin. We posited that the presence on the aryl ketone of the electron-donating 4-methoxy or -hydroxy groups commonly found in lignin might inhibit the pinacol-forming reductive dimerization.

The results of these experiments are summarized in Table 2 and Fig. S13-S18. $\dagger$ Electric current $(5 \mathrm{~mA})$ alone still cleaved the $\beta$-O-4 dimers bearing methoxy substituents. As expected, with pre-electrolyzed 2,2'-dithiodiethanol (1 eq.), the cleavage time was shortened, except in the case of dimer $\mathbf{1 b}$ where the substituent para to the ketone moiety is $-\mathrm{OH}$. We speculate that this phenolic - $\mathrm{OH}$ in $\mathbf{1 b}$ may be deprotonated, forming a quinone methide intermediate which would resist further reduction and cleavage of the ether bond (Scheme $\mathrm{S} 2 \dagger$ ). Without addition of the disulfide, an "induction period" (around $45 \mathrm{~min}$ ) was found in the electrolysis of both dimers 1a and 1c where very limited dimer cleavages occurred

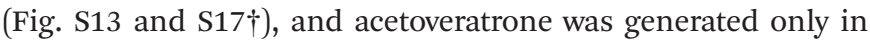
moderate yields. Pre-electrolysis of the disulfide shortened the induction time by half (Fig. S14 and S18 ${ }^{\dagger}$ ) and improved the yields of acetoveratrone to $72 \%$ (dimer 1a) and $45 \%$ (dimer 1c), with quantitative yields of guaiacol (dimer 1a) and 53\% syringol (dimer 1c), respectively. Termination of the reaction prior to acetoveratrone decay, which usually occurred after the dimers were consumed (i.e., at $1.5 \mathrm{~h}$ for $\mathbf{1 a}$ and at $2 \mathrm{~h}$ for $\mathbf{1 c}$ ), would help maximize the monomer yields (Fig. S14 and S18 $\dagger$ ). As expected, more promising results were observed when BHT and RSSR were pre-electrolyzed together. All the monomeric products were produced in $1.5 \mathrm{~h}$ with over $90 \%$ yields (Fig. S19 and $\mathrm{S} 20 \dagger$ ). Notably, dimer $1 \mathrm{a}$, which required $24 \mathrm{~h}$ to produce a quantitative yield of acetoveratrone in the previous study (employing refluxing acetonitrile with 10 eq. $\beta$-mercaptoethanol and a large excess of $\left.\mathrm{K}_{2} \mathrm{CO}_{3}\right),{ }^{38}$ decomposed to acetoveratrone (91\%) and guaiacol (90\%) using 1 eq. of 2,2'-dithiodiethanol at room temperature in only $1.5 \mathrm{~h}$ (Fig. S19†) in the current study. Together, the shortened reaction time, lower reaction temperature, and significantly reduced thio-compound loading suggest that electrochemical 
Table 2 Thio-assisted electrolysis of other $\beta-0-4$ dimers bearing methoxy groups

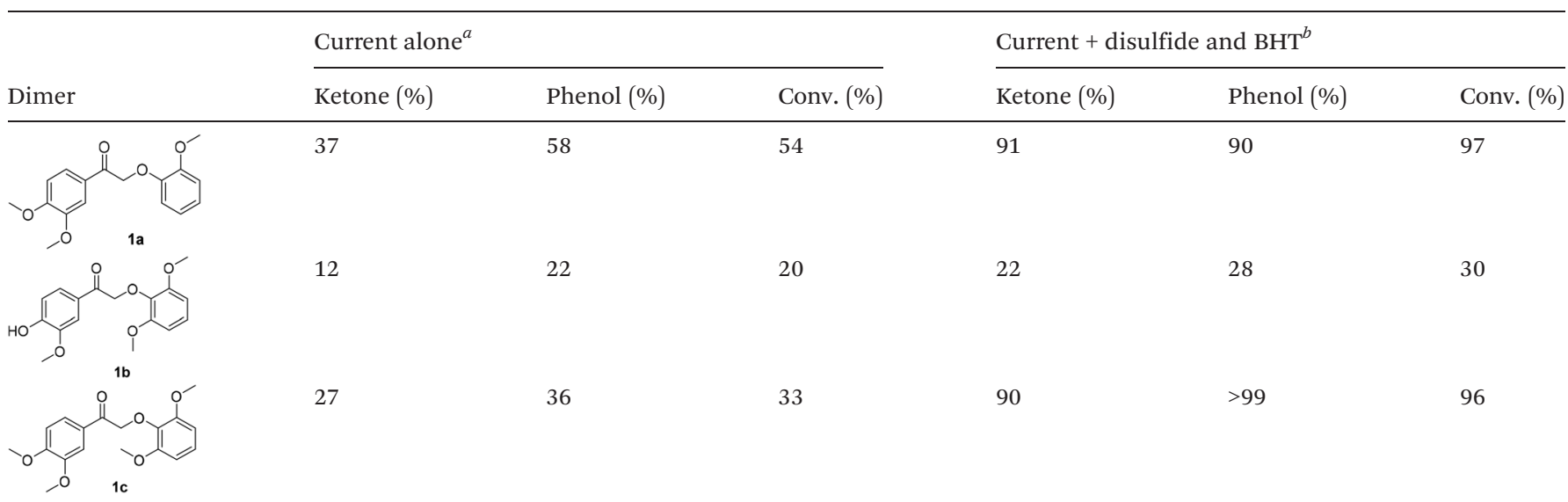

${ }^{a}$ The reaction was performed in DMF with $5 \mathrm{~mA}$ only (no disulfide) at room temperature for $2 \mathrm{~h} .{ }^{b}$ The disulfide $\left(2,2^{\prime}\right.$-dithiodiethanol) and BHT (1:1 molar ratio) were pre-electrolyzed together for $40 \mathrm{~min}$ in DMF at $5 \mathrm{~mA}$, and the dimer was then added and the reaction stirred for $1.5 \mathrm{~h}$.

depolymerization might succeed under practical conditions with authentic lignin.

\section{Thio-assisted electrolysis of lignin ${ }^{o x}$}

The successful cleavage of the model $\beta-0-4$ lignin dimers described above encouraged us to apply the optimized conditions to authentic lignin samples. The lignin used in this study was extracted from hybrid poplar following the previous described copper-catalyzed alkaline peroxide (Cu-AHP) strategy. ${ }^{49} \mathrm{Cu}$-AHP lignin was oxidized (referred to as lignin ${ }^{\text {ox }}$ ) with 2,3-dichloro-5,6-dicyano-1,4-benzoquinone (DDQ), ${ }^{10}$ which was confirmed by 2D HSQC spectra (Fig. S21†). To improve the conductivity of the reaction mixture and the solubility of lignin $^{\text {ox }}$, a solvent mixture of $\mathrm{pH} 8$ phosphate buffer/isopropanol $(2: 1, \mathrm{v} / \mathrm{v})$ was employed and the reaction was performed under a higher current density $\left(10 \mathrm{~mA} \mathrm{~cm}^{-2}\right)$ for $6 \mathrm{~h}$.

Electric current was found to be critical in this aqueous reaction system as lignin ${ }^{\text {ox }}$ showed essentially no change in the absence of flowing current. This is consistent with our previous finding that water inhibited the thio-assisted keto aryl ether cleavage. In the previous study, increased thiol loading, elevated temperature and $\mathrm{N}_{2}$ protection were required to break the ether bond. ${ }^{38}$ In contrast, at room temperature, the combination of electric current and disulfide successfully solubilized $62 \%$ of lignin ${ }^{\text {ox }}$ in only $6 \mathrm{~h}$ (Fig. 6) while only $46 \%$ of the lignin $^{\text {ox }}$ was solubilized under analogous conditions in the absence of the disulfide, again demonstrating that the thiol assists in the lignin cleavage process. In the control reaction where no disulfide was added, electric current $(20 \mathrm{~mA})$ alone afforded $24 \mathrm{wt} \%$ of ethyl acetate soluble (EA soluble) products from lignin ${ }^{\text {ox }}$ (Fig. 6), including various functionalized $\mathrm{S} / \mathrm{G} / \mathrm{H}$ type phenolic monomers (Fig. 7) along with a series of dimers, trimers, tetramers and other oligomers (Fig. S22 $\dagger$ ). The addition of RSSR (2,2'-dithiodiethanol) and BHT to the reaction mixture improved the yield of EA soluble products to $36 \mathrm{wt} \%$, with a concomitant decrease in the insoluble material

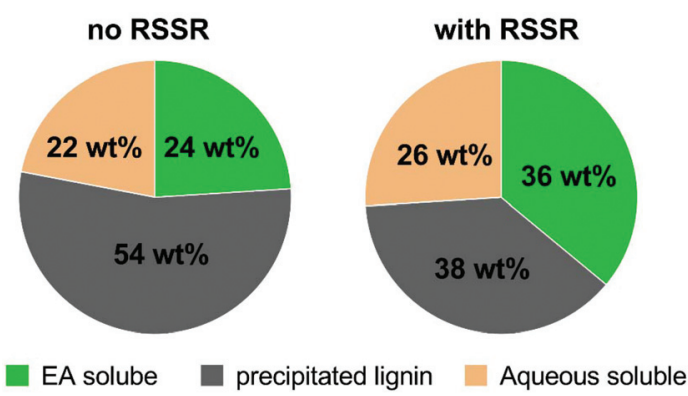

Fig. 6 Composition of each fraction from electrolysis of lignin ${ }^{\circ x}$; wt\% of each fraction was calculated based on the weight of lignin ${ }^{\circ}$. Note: wt\% of aqueous-soluble fraction was determined by 1 - (wt\% of EA soluble $+w t \%$ of insoluble).

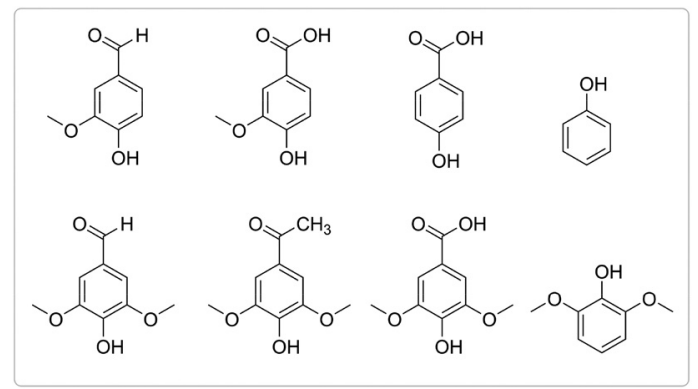

Fig. 7 Phenolic monomers from electrolysis of lignin ${ }^{\circ x}$; products were determined by GC-MS.

from $54 \mathrm{wt} \%$ to $38 \mathrm{wt} \%$ (Fig. 6). Although slight differences were observed via LCMS-QTOF in the distribution of products in the EA soluble fractions (Fig. S23†), the profiles were relatively similar, indicating that the addition of the disulfide did not significantly complicate the product streams. Addition of disulfide and BHT increased the amount of aqueous soluble products from $22 \mathrm{wt} \%$ to $26 \mathrm{wt} \%$, and analysis by gel per- 
meation chromatography (GPC) indicated that the molecular weight of the major products ranged from approximately 600-1000 Da (Fig. S24†). Overall, at ambient temperature and atmosphere, electroreductive degradation of lignin ${ }^{\text {ox }}$ solubilized a significant fraction of the lignin, leaving only 38-54 wt\% of insoluble residual. Compared to previous work on depolymerization of different types of lignin, i.e. via catalytic electrolysis (77-82 $\mathrm{wt} \%$ residual), ${ }^{50}$ aerobic oxidationhydrolysis (47-78 wt $\%$ residual $)^{9}$ or a two-step oxidative approach (50-91 wt\% residual), ${ }^{10}$ the present study represents an encouraging first step in developing a simple new strategy for lignin depolymerization and valorization.

\section{Conclusion}

Building on our previously reported thiolate-based reductive cleavage of $\beta-\mathrm{O}-4$ linkages via an $\mathrm{S}_{\mathrm{N}} 2$ pathway, ${ }^{38,39}$ this study aimed to electrochemically reduce the disulfide byproduct to achieve an electrocatalytic cycle (Fig. 1). Electrolytic reductive treatment of $\alpha$-keto $\beta$-O- 4 model dimers together with disulfides does indeed result in ether cleavage. With pre-electrolyzed disulfide and BHT, this approach cleaved the $\beta$-O-4 models and produced the corresponding phenolic and keto monomers with over $90 \%$ yields in only $1.5 \mathrm{~h}$. Using only 1 eq. of disulfide at room temperature, this surprisingly mild and rapid cleavage represented an unexpectedly large improvement over our previous mechanistically motivated work in which 10 eq. of thiol in refluxing acetonitrile required $24 \mathrm{~h}$ to completely cleave the oxidized $\beta-\mathrm{O}-4$ dimers. Applied to preoxidized authentic lignin, the electrochemical method showed promising levels of cleavage and solubilization. In the electrochemical context, the use of thiols, originally envisioned to serve as small diffusible redox carriers via the thiol/disulfide couple, enables a significantly milder approach to deconstruction of lignin to small-molecule fragments. Though the mechanistic details of these improvements remain incompletely understood, we summarize our findings as follows: (1) prereduction of the disulfide forms active species that promote cleavage of 2-phenoxyacetophenone; (2) for complete substrate conversion, electric current must be supplied throughout the reaction time; (3) dimer cleavage is not likely to involve free thiyl radicals; and (4) substrate is cleaved faster under a $\mathrm{N}_{2}$ atmosphere than under air. These results represent a substantial step forward in linking the reducing power of electrical current to the deconstruction and potential valorization of lignin as an organic feedstock.

\section{Experimental section}

\section{General materials}

Acetone (ACS grade), 3,4-dimethoxyacetophenone (98\%), 4-hydroxy-3-methoxyacetophenone (acetovanillone, 98\%), 2,6di-tert-butyl-4-methylphenol (BHT, >99\% GC), 1-phenylethanol (98\%), acetonitrile (99.5+\%), dichloromethane (ACS grade),
$N$-bromosuccinimide (NBS, 99\%), lithium tetrafluoroborate $\left(\mathrm{LiBF}_{4}, 98 \%\right.$ ), N,N-dimethylformamide (DMF, 99.8\%, anhydrous), syringol, 2,3-diphenyl-butane-2,3-diol (pinacol), hexane (>98.5\%), and plastic silica gel $60 \mathrm{~F}-254$ plates (for thin layer chromatography, TLC) were purchased from SigmaAldrich (St Louis, MO). Acetophenone (98.8\%) and triethyl amine were purchased from J.T. Baker (Phillipsburg, NJ), while benzyl chloride and 2-phenoxyacetophenone (>98\%) were purchased from TCI, America, Ltd (Portland, OR). Guaiacol (99+ $\%$ was purchased from Acros Organics (New Jersey). Tetrahydrofuran (THF, 99+\% with 250 ppm BHT) and phenol (99+\%) were purchased from Alfa Aesar (Haverhill, MA). Sodium sulfate (anhydrous) and ethyl acetate (99.9\%) were purchased from Fisher Chemicals (Pittsburgh, PA), and $p$-toluenesulfonic acid ( $\mathrm{TsOH})$ was purchased from Spectrum (New Brunswick, NJ). Finally, Chloroform- $d\left(\mathrm{CDCl}_{3}, 99.8\right.$ atom\% D) was purchased from Cambridge Isotope Laboratories (Andover, MA).

\section{Characterization of products}

Column chromatography was performed on Silicycle (Quebec City, Canada) SiliaFlash P60 silica gel $(40-63 \mu \mathrm{m}) .{ }^{1} \mathrm{H}$ and ${ }^{13} \mathrm{C}$ NMR spectra were acquired on Agilent 500/54 premium shielded instruments with tetramethylsilane or residual solvent as the internal reference. High performance liquid chromatography (HPLC) was conducted on an Agilent 1260 Infinity equipped with an Agilent G1315D1260 diode array detector VL, monitoring at $250 \mathrm{~nm}$ (for experiments related to dimer 1a-c) or $280 \mathrm{~nm}$ (for experiments related to 2-phenoxyacetophenone) and recording 190-400 nm. A 10 L sample injection using a Supelco Ascentis Express C18 column $(15 \mathrm{~cm} \times$ $4.6 \mathrm{~cm}, 2.7 \mu \mathrm{m}$, St Louis, MO) at $0.5 \mathrm{~mL} \mathrm{~min}^{-1}$, with a mobile phase of 35/65 and 50/50 acetonitrile/water (with $0.5 \mathrm{M} \mathrm{H}_{2} \mathrm{SO}_{4}$ ) was applied at $30^{\circ} \mathrm{C}$ on analyses of 1a-c and 2-phenoxyacetophenone related experiments, respectively. Yields of products were calibrated using authentic compounds as external standards. Gel permeation chromatography (GPC) was performed using a Waters Ultrahydrogel $2507.8 \times 300 \mathrm{~mm}$ column equipped with a Waters Ultrahydrogel $6 \times 40 \mathrm{~mm}$ guard column at $40{ }^{\circ} \mathrm{C}$ with a mobile phase of $5 \mathrm{mM} \mathrm{NaOH}$ in $80 / 20$ $0.1 \mathrm{M}$ aqueous sodium nitrate/acetonitrile at a flow rate of $0.7 \mathrm{~mL} \mathrm{~min}^{-1}$. Polystyrene sulfonic acid and poly(ethylene glycol) were employed as external standards. ${ }^{1} \mathrm{H}^{13} \mathrm{C}$-gradient heteronuclear single quantum coherence (HSQC) was performed at ambient temperature on a $500 \mathrm{MHz}$ Bruker NMR spectrometer equipped with a $5 \mathrm{~mm}$ iProbe (BBO probe). Spectra were collected by utilizing the Bruker pulse sequence "hsqcedetgpsisp2.3" with an acquisition time of $63.9 \mathrm{~ms}$ (F2, 512 complex points for ${ }^{1} \mathrm{H}$ ) and $63.9 \mathrm{~ms}$ (F1, 1024 increments for the ${ }^{13} \mathrm{C}$ dimension), using a delay of $1.5 \mathrm{~s}$ with 48 scans per increment with spectral widths of $8013 \mathrm{~Hz}\left({ }^{1} \mathrm{H}\right)$ and $20 \mathrm{kHz}\left({ }^{13} \mathrm{C}\right)$.

\section{General procedure for thio-assisted cathodic electrolysis of dimers}

Reactions were conducted at room temperature up to $2.5 \mathrm{~h}$ in an H-type electrochemical cell (separated by a Nafion 117 mem- 
brane) wherein a platinum wire in $20 \mathrm{~mL}$ of $\mathrm{pH} 8$ phosphate buffer was placed in the anode half-cell and the reticulated vitreous carbon (RVC, $2 \mathrm{~cm}^{2}$ immersed) was employed as the cathode. The start of the reaction $(t=0)$ was defined as the time point when substrate (2-phenoxyacetophenone or dimers 1a-c) was added. (Note: reactions were run in open air unless otherwise noted.)

For reactions run without pre-electrolysis, $20 \mathrm{mg}$ of the dimer (2-phenoxyacetophenone or 1a-c), 2,2'-dithiodiethanol (none or 1 eq.) and BHT (none or 1 eq.) were directly added to $20 \mathrm{~mL}$ DMF in the cathode half-cell and a $5 \mathrm{~mA}$ electric current was applied for the duration of the reaction (the voltage of the system ranged from 5.6-6.0 V in DMF under our conditions). Sample aliquots $(250 \mu \mathrm{L})$ were taken from the cathode cell at timed intervals and diluted with another $250 \mu \mathrm{L}$ of acetonitrile before HPLC analysis.

For reactions involving pre-electrolysis of the disulfide $\left(2,2^{\prime}\right.$ dithodiethanol), 2,2'-dithiodiethanol alone was added to $20 \mathrm{~mL}$ DMF and the $5 \mathrm{~mA}$ electric current was applied for $30 \mathrm{~min}$ or $1 \mathrm{~h}$. Then, $20 \mathrm{mg}$ of the dimer (2-phenoxyacetophenone or $\mathbf{1 a - c )}$ ) and BHT (none or 1 eq.) were added in solid form. Sampling for HPLC analysis was performed as above.

For reactions run under a $\mathrm{N}_{2}$ atmosphere: $20 \mathrm{~mL}$ of $\mathrm{DMF}$ alone was placed in the sealed cathode half-cell and the cell was purged with $\mathrm{N}_{2}$ for 30 min with stirring. Subsequent steps were as described above except that a $\mathrm{N}_{2}$ balloon was connected to the cathode half-cell throughout the reaction. At different time intervals, $500 \mu \mathrm{L}$ samples were taken from the cathode cell for HPLC analysis.

\section{Synthesis of $\beta-0-4$ dimers (1a-c)}

Dimers 1a-c were synthesized based on previous reports with only minor modifications. ${ }^{38}$

1-(3,4-Dimethoxyphenyl)-2-(2-methoxyphenoxy)ethan-1-one (1a). A solution of $N$-bromosuccinimide (NBS, $1.96 \mathrm{~g}$, $11.1 \mathrm{mmol})$ dissolved in anhydrous acetonitrile $(20 \mathrm{~mL})$ was added dropwise with stirring to a solution of 3,4-dimethoxyacetophenone ( $2 \mathrm{~g}, 11.1 \mathrm{mmol})$ and $p$-toluenesulfonic acid $(\mathrm{TsOH}$, $3.2 \mathrm{~g}, 16.6 \mathrm{mmol})$ in anhydrous acetonitrile $(30 \mathrm{~mL})$. The mixture was heated to $100{ }^{\circ} \mathrm{C}$ and stirred for $2 \mathrm{~h}$ under a $\mathrm{N}_{2}$ atmosphere. After cooling to room temperature, the solvent was evaporated in vacuo. The crude product was redissolved in dichloromethane (DCM, $30 \mathrm{~mL}$ ) and washed three times with $30 \mathrm{~mL}$ aliquots of deionized water. The organic layer was separated and dried with anhydrous $\mathrm{Na}_{2} \mathrm{SO}_{4}$ and concentrated under vacuum. The crude product was purified by column chromatography on silica gel (hexane/ethyl acetate $=2 / 1$ ) to produce 2-bromo-1-(3,4-dimethoxyphenyl)ethanone $(2.54 \mathrm{~g}$, $9.8 \mathrm{mmol}$ ) as a white solid in $88 \%$ yield.

A mixture of 2-bromo-1-(3,4-dimethoxyphenyl)ethanone $(2.54 \mathrm{~g}, 9.8 \mathrm{mmol})$, guaiacol $(1.21 \mathrm{~g}, 9.8 \mathrm{mmol})$, and $\mathrm{K}_{2} \mathrm{CO}_{3}$ $(1.35 \mathrm{~g}, 9.8 \mathrm{mmol})$ in acetone $(50 \mathrm{~mL})$ was stirred at room temperature overnight. The solid was removed by vacuum filtration and the solution was extracted with three $20 \mathrm{~mL}$ aliquots of DCM. The combined organic layers were separated and dried with anhydrous $\mathrm{Na}_{2} \mathrm{SO}_{4}$ and concentrated under vacuum. The crude product was purified by column chromatography on silica gel (hexane/ethyl acetate $=2 / 1$ ) to produce $\mathbf{1 a}$ $(2.65 \mathrm{~g}, 8.8 \mathrm{mmol})$ as a white solid in $89 \%$ yield.

${ }^{1} \mathrm{H} \mathrm{NMR}\left(500 \mathrm{MHz}, \mathrm{CDCl}_{3}\right): 7.69(\mathrm{dd}, J=8.4,2.0 \mathrm{~Hz}, 1 \mathrm{H})$, $7.61(\mathrm{~d}, J=2.0 \mathrm{~Hz}, 1 \mathrm{H}), 7.01-6.94(\mathrm{~m}, 1 \mathrm{H}), 6.94-6.88(\mathrm{~m}, 2 \mathrm{H})$, 6.88-6.82 (m, 2H), $5.31(\mathrm{~s}, 2 \mathrm{H}), 3.96(\mathrm{~s}, 3 \mathrm{H}), 3.94(\mathrm{~s}, 3 \mathrm{H}), 3.90$ $(\mathrm{s}, 3 \mathrm{H}) ;{ }^{13} \mathrm{C} \mathrm{NMR}\left(126 \mathrm{MHz}, \mathrm{CDCl}_{3}\right):$ 193.2, 153.7, 149.6, 149.1, $147.5,127.8,122.7,122.3,120.8,114.6$, 112.0, 110.4, 110.1, 71.9, 56.1, 56.0, 55.9. Spectral data are in accordance with those previously reported. ${ }^{38}$

2-(2,6-Dimethoxyphenoxy)-1-(4-hydroxy-3-methoxyphenyl)ethan1-one (1b). Benzyl chloride (9.1 g, $72 \mathrm{mmol}$ ) was added dropwise to a solution of DMF containing acetovanillone $(10 \mathrm{~g}$, $60 \mathrm{mmol}), \mathrm{K}_{2} \mathrm{CO}_{3}(12.5 \mathrm{~g}, 90 \mathrm{mmol})$ and $\mathrm{KI}(0.2 \mathrm{~g}, 1.2 \mathrm{mmol})$, and the resulting solution was stirred at $40{ }^{\circ} \mathrm{C}$ overnight. The mixture was poured into ice water and the solid precipitate was filtered and washed with DI water. Drying in the vacuum oven $\left(50{ }^{\circ} \mathrm{C}\right)$ gave $14.3 \mathrm{~g}$ of the benzyl protected acetovanillone in a yield of $93 \%$.

A solution of $N$-bromosuccinimide (NBS, $6.96 \mathrm{~g}, 39 \mathrm{mmol}$ ) dissolved in anhydrous acetonitrile $(30 \mathrm{~mL})$ was added dropwise with stirring to a solution of the above benzyl protected acetovanillone (10 g, $39 \mathrm{mmol})$ and $p$-toluenesulfonic acid $(\mathrm{TsOH}, 10 \mathrm{~g}, 58.6 \mathrm{mmol})$ in anhydrous acetonitrile $(70 \mathrm{~mL})$. The mixture was then heated and stirred at $100{ }^{\circ} \mathrm{C}$ for $2 \mathrm{~h}$ under a $\mathrm{N}_{2}$ atmosphere. After cooling to room temperature, the solvent was evaporated in vacuo. The crude product was redissolved in dichloromethane (DCM, $70 \mathrm{~mL}$ ) and washed three times with $30 \mathrm{~mL}$ aliquots of deionized water. The organic layer was separated and dried with anhydrous $\mathrm{Na}_{2} \mathrm{SO}_{4}$ and concentrated under vacuum. Without further purification, the resulting crude protected bromoacetovanillone (5 g, $14.9 \mathrm{mmol}$ ) was combined with syringol (2.3 g, $14.9 \mathrm{mmol})$ and $\mathrm{K}_{2} \mathrm{CO}_{3}(2.06 \mathrm{~g}, 14.9 \mathrm{mmol})$ in acetone $(100 \mathrm{~mL})$ and stirred at room temperature overnight. The solid $\mathrm{KBr}$ byproduct was removed by vacuum filtration and the solution was extracted with three $30 \mathrm{~mL}$ aliquots of DCM. The organic layers were combined and dried with anhydrous $\mathrm{Na}_{2} \mathrm{SO}_{4}$ and concentrated under vacuum. The resulting crude protected dimer $(2 \mathrm{~g})$ was dissolved in methanol (50 mL), 10\% Pd/C (0.2 g) was added, and the mixture was stirred for $3 \mathrm{~h}$ at room temperature. The solid catalyst was separated by vacuum filtration and washed with methanol. Then, the filtrate was concentrated under vacuum and the crude product was purified by column chromatography on silica gel (hexane/ethyl acetate $=2 / 1$ ) to give a yellow solid.

${ }^{1} \mathrm{H}$ NMR (500 MHz, $\left.\mathrm{CDCl}_{3}\right):$ 7.69-7.64 (m, 2H), $7.02(\mathrm{t}, J=$ $8.4 \mathrm{~Hz}, 1 \mathrm{H}), 6.95(\mathrm{~d}, J=8.1 \mathrm{~Hz}, 1 \mathrm{H}), 6.59(\mathrm{~d}, J=8.4 \mathrm{~Hz}, 2 \mathrm{H})$, 5.16 (s, 2H), 3.96 (s, 3H), $3.82(\mathrm{~s}, 6 \mathrm{H}) ;{ }^{13} \mathrm{C}$ NMR $(126 \mathrm{MHz}$, $\left.\mathrm{CDCl}_{3}\right): 193.5,153.2,150.5,146.6,136.6,128.0,124.0,123.5$, $113.8,110.4,105.3,75.2,56.1,56.1$. Spectral data are in accordance with those previously reported. ${ }^{38}$

2-(2,6-Dimethoxyphenoxy)-1-(3,4-dimethoxyphenyl)ethan1-one (1c). A mixture of 2-bromo-1-(3,4-dimethoxyphenyl)ethanone (5 g, $19.3 \mathrm{mmol}$ ), syringol ( $3 \mathrm{~g}, 19.3 \mathrm{mmol})$, and $\mathrm{K}_{2} \mathrm{CO}_{3}$ $(2.66 \mathrm{~g}, 19.3 \mathrm{mmol})$ in acetone $(100 \mathrm{~mL})$ was stirred at room 
temperature overnight. The solid was removed by vacuum filtration, and the solution was extracted with three $30 \mathrm{~mL}$ aliquots of DCM. The combined organic layers were separated and dried with anhydrous $\mathrm{Na}_{2} \mathrm{SO}_{4}$ and concentrated under vacuum. The crude product was purified by column chromatography on silica gel (hexane/ethyl acetate $=2 / 1$ ) to produce $1 \mathrm{c}$ $(4.8 \mathrm{~g}, 14.4 \mathrm{mmol})$ as a white solid in $75 \%$ yield.

${ }^{1} \mathrm{H}$ NMR (500 MHz, $\left.\mathrm{CDCl}_{3}\right): 7.73(\mathrm{dd}, J=8.3,2.0 \mathrm{~Hz}, 1 \mathrm{H})$, $7.66(\mathrm{~d}, J=2.0 \mathrm{~Hz}, 1 \mathrm{H}), 7.02(\mathrm{t}, J=8.4 \mathrm{~Hz}, 1 \mathrm{H}), 6.90(\mathrm{~d}, J=$ $8.4 \mathrm{~Hz}, 1 \mathrm{H}), 6.59$ (d, $J=8.5 \mathrm{~Hz}, 2 \mathrm{H}), 5.16(\mathrm{~s}, 2 \mathrm{H}), 3.95(\mathrm{~d}, J=$ $1.8 \mathrm{~Hz}, 6 \mathrm{H}), 3.82(\mathrm{~s}, 6 \mathrm{H}) ;{ }^{13} \mathrm{C}$ NMR (126 MHz, $\left.\mathrm{CDCl}_{3}\right)$ : 193.7, $153.4,153.3,153.2,148.9,136.6,128.3,124.0,123.0,110.6$, $110.0,105.2,105.2,75.2,56.0,56.0,56.0,55.9$. Spectral data are in accordance with those previously reported. ${ }^{38}$

\section{Oxidation of Cu-AHP lignin}

Lignin from alkaline pre-extracted hybrid poplar was isolated via the Cu-AHP pretreatment process as previously described using $1 \mathrm{mM}$ of copper and $2 \mathrm{mM}$ of bipyridine. ${ }^{49}$ Hydrogen peroxide $\left(\mathrm{H}_{2} \mathrm{O}_{2}, 100 \mathrm{mg}\right.$ per $\mathrm{g}$ of biomass $)$ was added in 10 equal aliquots at $1 \mathrm{~h}$ intervals while shaking at $30{ }^{\circ} \mathrm{C}$. DDQcatalyzed oxidation of $\mathrm{Cu}$-AHP lignin was performed following a previous literature report. ${ }^{10}$ Briefly, $3 \mathrm{~g}$ of lignin was solubilized in 1,2-dimethoxyethane/2-ethoxyethanol $(\mathrm{v} / \mathrm{v}=3: 2$, $42 \mathrm{~mL}$ ) and then DDQ (10 wt\%) and $t$-BuONO (10 wt\%) were added. The solution was heated at $80{ }^{\circ} \mathrm{C}$ overnight under an oxygen atmosphere. The oxidized lignin product $\left(\right.$ lignin $^{\mathrm{ox}}$ ) was precipitated by addition of $500 \mathrm{~mL}$ of diethyl ether, isolated by filtration, washed with additional diethyl ether $(200 \mathrm{~mL})$, and dried in vacuo, yielding $2.7 \mathrm{~g}$ of light-brown lignin ${ }^{\mathrm{ox}}$.

\section{General procedure for thio-assisted electrolysis of lignin ${ }^{\text {ox }}$}

Reactions were conducted at room temperature in an H-type electrochemical cell (separated by a Nafion 117 membrane) with $20 \mathrm{~mL}$ of $\mathrm{pH} 8$ phosphate buffer and $20 \mathrm{~mL}$ of $2: 1, \mathrm{v} / \mathrm{v}$ pH 8 phosphatebuffer/isopropanol in the anodic and cathodic cell, in which a platinum wire was used as the anode and reticulated vitreous carbon (RVC) was employed as the cathode, respectively. A mixture of $\mathrm{LiBF}_{4}(100 \mathrm{mg})$ and $\mathrm{BHT}$ (100 mg) was added into the cathodic cell. After $1 \mathrm{~h}$ of pre-electrolysis at $20 \mathrm{~mA}$ (current density $\left.=10 \mathrm{~mA} \mathrm{~cm}{ }^{-2}\right)$, lignin ${ }^{\text {ox }}(100 \mathrm{mg}$ ) and 2,2'-dithiodiethanol (RSSR, $100 \mathrm{mg}$ ) were added to the catholyte and the reaction continued at $20 \mathrm{~mA}$ for an additional $6 \mathrm{~h}$. The solvent was removed under a $\mathrm{N}_{2}$ flow, and the crude product was solubilized in $20 \mathrm{~mL}$ EtOAc/water $(1: 1, \mathrm{v} / \mathrm{v})$. The solution was acidified with $60 \% \mathrm{H}_{2} \mathrm{SO}_{4}$ to $\mathrm{pH} 2$, precipitating insoluble material. The precipitate was filtered, washed with water, dried in vacuo, and the remaining filtrate was extracted three times with $30 \mathrm{~mL}$ EtOAc. The organic layers were combined, dried with anhydrous $\mathrm{Na}_{2} \mathrm{SO}_{4}$, and concentrated in vacuo. In the parallel control reaction, all set-up and work-up protocols were the same except that the RSSR and BHT components were omitted.

\section{Conflicts of interest}

A patent application has been submitted by E. L. Hegg, J. E. Jackson, and G. E. Klinger (Methods for Lignin Depolymerization Using Thiols - WO/2018/195000). As holders of this patent application, we could potentially benefit financially from the technology discussed in this manuscript.

\section{Acknowledgements}

This material is based upon work supported by the Great Lakes Bioenergy Research Center, U.S. Department of Energy, Office of Science, Office of Biological and Environmental Research under Award Number DE-SC0018409. The authors gratefully acknowledge Casey Johnny and Tony Schilmiller in the Research Technology Support Facility at Michigan State University for the GC-MS and LCMS-TOF analyses. ZF thanks Nicholas Schlecht for help in performing selected reactions and Dr. Md Asmaul Hoque at UW-Madison for running the cyclic voltammetry of 2,2'-dithiodiethanol (Fig. S31†).

\section{Notes and references}

1 J. Zakzeski, P. C. A. Bruijnincx, A. L. Jongerius and B. M. Weckhuysen, Chem. Rev., 2010, 110(6), 3552-3599.

2 Z. Sun, B. Fridrich, A. de Santi, S. Elangovan and K. Barta, Chem. Rev., 2018, 118(2), 614-678.

3 W. Schutyser, T. Renders, S. Van den Bosch, S. F. Koelewijn, G. T. Beckham and B. F. Sels, Chem. Soc. Rev., 2018, 47(3), 852-908.

4 B. M. Upton and A. M. Kasko, Chem. Rev., 2016, 116(4), 2275-2306.

5 C. Li, X. Zhao, A. Wang, G. W. Huber and T. Zhang, Chem. Rev., 2015, 115(21), 11559-11624.

6 I. Hasegawa, Y. Inoue, Y. Muranaka, T. Yasukawa and K. Mae, Energy Fuels, 2011, 25(2), 791-796.

7 A. Rahimi, A. Azarpira, H. Kim, J. Ralph and S. S. Stahl, J. Am. Chem. Soc., 2013, 135(17), 6415-6418.

8 A. Rahimi, A. Ulbrich, J. J. Coon and S. S. Stahl, Nature, 2014, 515(7526), 249-252.

9 A. Das, A. Rahimi, A. Ulbrich, M. Alherech, A. H. Motagamwala, A. Bhalla, L. da Costa Sousa, V. Balan, J. A. Dumesic, E. L. Hegg, B. E. Dale, J. Ralph, J. J. Coon and S. S. Stahl, ACS Sustainable Chem. Eng., 2018, 6(3), 3367-3374.

10 Y. Song, A. H. Motagamwala, S. D. Karlen, J. A. Dumesic, J. Ralph, J. K. Mobley and M. Crocker, Green Chem., 2019, 21(14), 3940-3947.

11 O. Musl, M. Holzlechner, S. Winklehner, G. Gübitz, A. Potthast, T. Rosenau and S. Böhmdorfer, ACS Sustainable Chem. Eng., 2019, 7(18), 15163-15172.

12 Y. Li, B. Demir, L. M. Vázquez Ramos, M. Chen, J. A. Dumesic and J. Ralph, Green Chem., 2019, 21(13), 3561-3572. 
13 E. Feghali, G. Carrot, P. Thuéry, C. Genre and T. Cantat, Energy Environ. Sci., 2015, 8(9), 2734-2743.

14 E. M. Anderson, R. Katahira, M. Reed, M. G. Resch, E. M. Karp, G. T. Beckham and Y. Román-Leshkov, ACS Sustainable Chem. Eng., 2016, 4(12), 6940-6950.

15 L. Fan, Y. Zhang, S. Liu, N. Zhou, P. Chen, Y. Cheng, M. Addy, Q. Lu, M. M. Omar, Y. Liu, Y. Wang, L. Dai, E. Anderson, P. Peng, H. Lei and R. Ruan, Bioresour. Technol., 2017, 241, 1118-1126.

16 G. Jiang, D. J. Nowakowski and A. V. Bridgwater, Energy Fuels, 2010, 24(8), 4470-4475.

17 P. R. Patwardhan, R. C. Brown and B. H. Shanks, ChemSusChem, 2011, 4(11), 1629-1636.

18 P. J. Deuss and K. Barta, Coord. Chem. Rev., 2016, 306, 510532.

19 S. K. Hanson and R. T. Baker, Acc. Chem. Res., 2015, 48(7), 2037-2048.

20 S. Van den Bosch, W. Schutyser, S. F. Koelewijn, T. Renders, C. M. Courtin and B. F. Sels, ChemComm, 2015, 51(67), 13158-13161.

21 C. H. Lam, S. Das, N. C. Erickson, C. D. Hyzer, M. Garedew, J. E. Anderson, T. J. Wallington, M. A. Tamor, J. E. Jackson and C. M. Saffron, Sustainable Energy Fuels, 2017, 1(2), 258266.

22 B. Mahdavi, A. Lafrance, A. Martel, J. Lessard, H. Ménard and L. Brossard, J. Appl. Electrochem., 1997, 27, 605-611.

23 A. Cyr, F. Chiltz, P. Jeanson, A. Martel, L. Brossard, J. Lessard and H. Ménard, Can. J. Chem., 2000, 78(3), 307315.

24 X. Du, H. Zhang, K. P. Sullivan, P. Gogoi and Y. Deng, ChemSusChem, 2020, 13(17), 4318-4343.

25 S. Stiefel, J. Lölsberg, L. Kipshagen, R. Möller-Gulland and M. Wessling, Electrochem. Commun., 2015, 61, 49-52.

26 B. A. Frontana-Uribe, R. D. Little, J. G. Ibanez, A. Palma and R. Vasquez-Medrano, Green Chem., 2010, 12(12), 20992119.

27 B. H. Nguyen, R. J. Perkins, J. A. Smith and K. D. Moeller, J. Org. Chem., 2015, 80(24), 11953-11962.

28 T. Wu, B. H. Nguyen, M. C. Daugherty and K. D. Moeller, Angew. Chem., Int. Ed., 2019, 58(11), 35623565.

29 V. L. Pardini, C. Z. Smith, J. H. P. Utley, R. R. Vargas and H. Viertler, J. Org. Chem., 1991, 56(26), 7305-7313.

30 H. Zhu, L. Wang, Y. Chen, G. Li, H. Li, Y. Tang and P. Wan, RSC Adv. , 2014, 4(56), 29917-29924.
31 Y.-S. Wang, F. Yang, Z.-H. Liu, L. Yuan and G. Li, Catal. Commun., 2015, 67, 49-53.

32 P. Parpot, A. P. Bettencourt, A. M. Carvalho and E. M. Belgsir, J. Appl. Electrochem., 2000, 30(6), 727-731.

33 R. Tolba, M. Tian, J. Wen, Z.-H. Jiang and A. Chen, J. Electroanal. Chem., 2010, 649(1-2), 9-15.

34 I. Bosque, G. Magallanes, M. Rigoulet, M. D. Karkas and C. R. J. Stephenson, ACS Cent. Sci., 2017, 3(6), 621-628.

35 M. Tian, J. Wen, D. MacDonald, R. M. Asmussen and A. Chen, Electrochem. Commun., 2010, 12(4), 527-530.

36 P. Dabo, A. Cyr, J. Lessard, L. Brossard and H. Ménard, Can. J. Chem., 1999, 77, 1225-1229.

37 Y. Zhou, G. E. Klinger, E. L. Hegg, C. M. Saffron and J. E. Jackson, J. Am. Chem. Soc., 2020, 142(8), 4037-4050.

38 G. E. Klinger, Y. Zhou, P. Hao, J. Robbins, J. M. Aquilina, J. E. Jackson and E. L. Hegg, ChemSusChem, 2019, 12(21), 4775-4779.

39 G. E. Klinger, Y. Zhou, J. A. Foote, A. M. Wester, Y. Cui, M. Alherech, S. S. Stahl, J. E. Jackson and E. L. Hegg, ChemSusChem, 2020, 13(17), 4394-4399.

40 S. Antonello, R. Benassi, G. Gavioli, F. Taddei and F. Maran, J. Am. Chem. Soc., 2002, 124(25), 7529-7538.

41 K. Nakahara, K. Naba, T. Saitoh, T. Sugai, R. Obata, S. Nishiyama, Y. Einaga and T. Yamamoto, ChemElectroChem, 2019, 6(16), 4153-4157.

42 A. Fava, G. Reichenbach and U. Peron, J. Am. Chem. Soc., 1967, 89(25), 6696-6700.

43 S. P. Mezyk and D. A. Armstrong, J. Chem. Soc., Perkin Trans. 2, 1999, (7), 1411-1420.

44 H. Wariishi, K. Valli, V. Renganathan and M. H. Gold, J. Biol. Chem., 1989, 264(24), 14185-14191.

45 X. Zhang, N. Zhang, H. P. Schuchmann and C. von Sonntag, J. Phys. Chem., 1994, 98, 6541-6547.

46 M. P. Bertrand, Org. Prep. Proced. Int., 1994, 26(3), 257-290.

47 C. P. Andrieux, M. Robert and J. M. Saveant, J. Am. Chem. Soc., 1995, 117, 9340-9346.

48 C. H. Lam, C. B. Lowe, Z. Li, K. N. Longe, J. T. Rayburn, M. A. Caldwell, C. E. Houdek, J. B. Maguire, C. M. Saffron, D. J. Miller and J. E. Jackson, Green Chem., 2015, 17(1), 601-609.

49 A. Bhalla, N. Bansal, R. J. Stoklosa, M. Fountain, J. Ralph, D. B. Hodge and E. L. Hegg, Biotechnol. Biofuels, 2016, 9, 34.

50 X. Du, W. Liu, Z. Zhang, A. Mulyadi, A. Brittain, J. Gong and Y. Deng, ChemSusChem, 2017, 10(5), 847-854. 